\title{
Libros en juego: bibliotecas populares y público infantil en el sudoeste bonaerense (Argentina, 1880-1930)
}

\author{
Maria de las Nieves Agesta ${ }^{1 *}$ \\ ${ }^{1}$ Universidad Nacional del Sur/CONICET, Bahía Blanca, Buenos Aires - Argentina
}

\section{RESUMEN}

El presente artículo analiza dos bibliotecas populares del sudoeste de la provincia de Buenos Aires (Argentina) -la Bernardino Rivadavia de Bahía Blanca fundada en 1882 y la Domingo F. Sarmiento de Tres Arroyos inaugurada en 1899- y la creación de sus respectivas secciones infantiles en 1925 y 1928, en articulación con el fenómeno de expansión de la educación pública y de la formación de un público infantil en la provincia. A fines de los años veinte es posible constatar allí un proceso de diversificación y de ampliación de los grupos lectores que fue producto y, a la vez, incentivo para la labor de las bibliotecas y sus transformaciones. Estas instituciones introdujeron modificaciones a fin de responder a la creciente demanda y pretendieron, no sin conflictos, asumir un rol activo en la configuración del nuevo lectorado, tanto mediante la regulación de los comportamientos y de los espacios de lectura como de la experiencia y los gustos de los usuarios.

Palabras clave: Bibliotecas; infancia; público lector; educación; Argentina.

\section{Livros em jogo: bibliotecas populares e público infantil no Sudoeste de Buenos Aires (Argentina, 1920-1930)}

\section{RESUMO}

Este artigo analisa duas bibliotecas populares do sudoeste da província de Buenos Aires (Argentina) - a Bernardino Rivadavia de Bahía Blanca, fundada em 1882, e a Domingo F. Sarmiento de Tres Arroyos, inaugurada em 1899 - e a criação das respectivas seçôes infantis

DOI: http://dx.doi.org/10.1590/2237-101X02104407

Artigo recebido em 12 de dezembro de 2018 e aceito para publicação em 10 de setembro de 2019.

* Professora da Universidad Nacional del Sur/CONICET / CER "Prof. Félix Weinberg"/ Departamento de Humanidades, Bahía Blanca, Buenos Aires - Argentina. E-mail: nievesagesta@uns.edu.ar. ORCID: https:// orcid.org/0000-0002-0586-1008 
em 1925 e 1928, em articulação com o fenômeno de expansão da educação pública e a formação de um público infantil na província. No final dos anos 1920, é possível verificar um processo de diversificação e ampliação dos grupos de leitura que foi um produto e, ao mesmo tempo, um incentivo para o trabalho da biblioteca e suas transformaçóes. Essas instituiçôes introduziram modificaçôes para responder à demanda crescente e pretendiam, não sem conflitos, assumir um papel ativo na configuração do novo leitorado, regulando tanto os comportamentos e os espaços de leitura quanto a experiência e os gostos dos usuários. Palavras-chave: bibliotecas; infância; público leitor; educação; Argentina.

\section{Game of books: popular libraries and child readership in Southwest Buenos Aires (Argentina, 1880-1930)}

\section{ABSTRACT}

This article analyzes two popular libraries in the southwest province of Buenos Aires, Argentina - the Bernardino Rivadavia of Bahía Blanca Library, founded in 1882, and the Domingo F. Sarmiento de Tres Arroyos Library, inaugurated in 1899-and the creation of their respective children's sections in 1925 and 1928. This paper looks at the formation of these children's sections within the context of expanding public education and child readership in the province. By the end of the 1920s, a verifiable process of expansion and diversification of reading groups had unfolded that was both a product of, and, at the same time, an incentive for further library development and its related transformations. These institutions introduced modifications in order to respond to the growing demand and tried to play an active role in the configuration of a new readership, both by regulating behaviors and reading spaces as well as experience and tastes of the users.

Key-words: libraries; childhood; readership; education; Argentina.

Desde fines del siglo XIX, Argentina fue protagonista de un proceso de modernización acelerada que implicó tanto la incorporación al circuito económico internacional como la apropiación de los valores civilizatorios occidentales. Fue entonces que se puso en marcha un programa educativo de alcance nacional que otorgó al libro una hegemonía indiscutida como dispositivo de transmisión de saberes, como instrumento de elevación moral y social, y como factor nacionalizador. En este contexto, tuvo su origen también la conformación de un sistema bibliotecario nacional que, a diferencia de lo sucedido en otros lugares, se estructuró en torno a la figura de la biblioteca popular. En este modelo se proponía una particular alianza 
entre la iniciativa privada de los grupos letrados y las distintas instancias gubernamentales comprometidas en su fomento. La multiplicación de las bibliotecas populares se insertó, entonces, como elemento fundamental en un proyecto educativo de largo alcance fundado sobre la difusión de la escuela elemental, laica y gratuita, y la legitimidad de la palabra escrita.

La provincia de Buenos Aires, a partir de las últimas dos décadas del siglo XIX, sufrió una expansión inusitada ligada a su doble carácter de litoral marítimo y de pastizal pampeano apto para el desarrollo agrícola-ganadero. El crecimiento económico y el exponencial aumento demográfico y urbano que lo acompañó, consolidaron su posición de preeminencia y justificaron las aspiraciones de progreso de las nuevas localidades creadas luego de la incorporación de las tierras expropiadas a los pueblos originarios a la organización productiva y al dominio estatal. La extensión de la alfabetización y del sistema educativo, en general, fueron consideradas como aspectos ineludibles del programa civilizatorio que seguía a la prosperidad económica y a la transformación poblacional. En este marco, la creación de bibliotecas populares fue concebida por las élites locales como una forma de intervención cultural con vocación pública que venía a reforzar el proyecto de un Estado nacional aún en consolidación, y también como una estrategia de construcción de la propia diferencia social. Estas instituciones en las poblaciones del interior bonaerense se convirtieron, así, en símbolos de progreso y en nodos de acción cultural, favoreciendo, en ocasiones, la equiparación de estas entidades surgidas de la sociedad civil con organismos de carácter público.

El presente artículo analiza dos bibliotecas populares del sudoeste de la provincia, la Bernardino Rivadavia de Bahía Blanca fundada en 1882 y la Domingo F. Sarmiento de Tres Arroyos inaugurada en 1899, y la creación de sus respectivas secciones infantiles en 1925 y 1928, en articulación con el proceso de expansión de la educación pública en las provincias y de la configuración de un público infantil. En efecto, a fines de los años veinte es posible constatar una diversificación de los grupos lectores, cada vez más amplios, que fue producto y, a la vez, incentivo para la labor bibliotecaria y sus transformaciones. Estas bibliotecas introdujeron modificaciones a fin de responder a la creciente demanda y pretendieron asumir un rol activo en la configuración del nuevo lectorado, tanto mediante la regulación de los comportamientos y de los espacios de lectura como de la experiencia y los gustos de los usuarios. Este proceso estuvo atravesado por tensiones permanentes no siempre explícitas con los entes oficiales encargados de su fomento que se fundaban sobre las contradicciones que suponía la convivencia entre la voluntad autonómica propia de las asociaciones y su necesidad de apelar a los recursos estatales para garantizar su supervivencia. Asimismo, la conformación de los catálogos bibliográficos implicó una serie de tensiones y negociaciones entre los dirigentes y los lectores habituales de la que no estuvieron excluidos factores como la expansión del mercado editorial, las modificaciones de la industria librera o las condiciones de posibilidad de acceso al material. 


\section{Educación y bibliotecas populares en la provincia de Buenos Aires}

La emergencia de instituciones bibliotecarias en la provincia de Buenos Aires, solo puede entenderse dentro de un proceso más amplio en el cual confluyeron, desde fines del siglo XIX, la denominada "explosión asociativa" y la implementación de un programa de extensión de la educación que se fundaban sobre la voluntad de modernizar el país de acuerdo a los cánones civilizatorios de la Europa industrial. Así, a diferencia de lo ocurrido en otras naciones latinoamericanas, en Argentina las bibliotecas populares constituyeron las unidades básicas a partir de las cuales se organizó el sistema bibliotecario desde 1870. Sin dudas, esta peculiaridad tuvo sus orígenes en un contexto caracterizado por la presencia de un Estado recientemente unificado y en vías de conformación y por la configuración a un modelo de crecimiento hacia afuera impulsado por una burguesía ligada a los intereses del capital extranjero. Este paradigma liberal suponía una valoración de la iniciativa privada y de la libertad individual como sustentos del desarrollo socio-económico y de la constitución de una esfera pública y de una ciudadanía moderna, en un marco de relativa inestabilidad política. De esta manera, el proyecto de expansión cultural y educativa fue entendido como una responsabilidad compartida entre el gobierno y la sociedad civil en ampliación y consolidación (SABATO, 1998). ${ }^{1}$

En efecto, el modelo introducido e impulsado por Domingo Faustino Sarmiento retomaba la experiencia estadounidense de los clubes de lectores organizados por Benjamin Franklin donde las asociaciones particulares constituían el bastión imprescindible del desarrollo bibliotecario posterior (PLANAS, 2015). Ya en su artículo "Espíritu de asociación" (1841), el sanjuanino sostenía que la iniciativa privada debía preceder el accionar gubernamental dado que, de acuerdo a su perspectiva, los pueblos que gozaban "del inestimable bien de la libertad" eran aquellos en los cuales proliferaban las asociaciones. Por ello, se volvía necesario promover la formación de "sociedades para fomentar la lectura de libros útiles, la difusión de los diarios entre los ciudadanos y la instrucción primaria en todas las clases de la sociedad" y, así, constituir bibliotecas en "cada aldea, villa o ciudad", "de este modo gobierna el pueblo, trabajando directamente y sin la intromisión de la autoridad alguna en procurarse su bienestar" (SARMIENTO, 1939, p. 13).

Aunque sosteniendo estas premisas, Sarmiento fue más tarde matizando sus ideas iniciales para proponer un sistema de bibliotecas donde deberían combinarse el esfuerzo público y el privado, que se concretó finalmente con la promulgación de la Ley 419 (1870) y la consiguiente creación de la Comisión Protectora de Bibliotecas Populares. Sí bien no pretendemos recuperar aquí el pensamiento sarmientino en su complejidad ni los avatares

\footnotetext{
${ }^{1}$ Es interesante comparar la conformación del sistema bibliotecario argentino con otros, como el mexicano, que se estructuraron en torno a la figura de la biblioteca pública. Véase v.g. QUINTANA PALI; GIL VILLEGAS; TOLOSA SÁNCHEZ, 1988.
} 
de esta primera etapa de funcionamiento de la Comisión que ya han sido analizados en detalle por Javier Planas, es menester destacar una vez más la relevancia de esta normativa para la formación de las bibliotecas decimonónicas. Como ha indicado este investigador, su derogación en 1876 supuso una disolución de la especificidad de la cuestión bibliotecaria en el más amplio campo educativo como consecuencia de su paso a manos de la Comisión Nacional de Escuelas. Habría que esperar hasta 1908 para que, bajo la presidencia de José Figueroa Alcorta y por decreto del Ministro de Educación Pública de la Nación Rómulo S. Naón, se restableciera el organismo burocrático desaparecido. Entre ambas fechas se produjo, según diversos autores, un período de retracción y de disminución de la actividad bibliotecaria y asociativa motivado por el cese de las subvenciones nacionales y la disminución del apoyo estatal. De acuerdo con estos estudios, la etapa 1890-1910 fue un momento de gestación dominado principalmente por las "bibliotecas obreras" allegadas a partidos o asociaciones afines a los intereses de esa clase y, solo en menor medida, a las de las asociaciones y clubes. ${ }^{2}$ La reposición legislativa marcaría, así, el comienzo de una nueva expansión que sería estimulada, además de por la militancia de izquierda y la intervención estatal, por la corriente de participación vecinal generada por el fomentismo, por el surgimiento de otros partidos políticos y por la Iglesia Católica (GUTIÉRREZ; ROMERO, 2007).

Estas afirmaciones, que resultan, sin dudas, verificables en el ámbito de Buenos Aires, deben matizarse en los espacios provincianos, donde los procesos tuvieron otras dinámicas históricas y otras cronologías. En la región que nos ocupa, el sudoeste de la provincia de Buenos Aires, la expansión económica, social y cultural tuvo lugar recién a partir de la década del ochenta cuando, como consecuencia de la campaña de exterminio y expulsión de las poblaciones originarias llevada adelante por el Estado nacional en 1879, se produjo una ocupación y una explotación efectivas y permanentes del territorio. Tanto Bahía Blanca (1828) como el partido Tres Arroyos (1865) fueron fundados con la intención de extender y afianzar la frontera sur y fueron protagonistas de un crecimiento inusitado a partir de la llegada del ferrocarril en 1884 y 1886, respectivamente, y la apertura del puerto próximo a Bahía Blanca en $1885 .{ }^{3}$ Estos acontecimientos supusieron su integración en el circuito productivo nacional e internacional, la primera como nodo ferro-portuario que le valió el mote de "Liverpool Argentina" (RIBAS, 2008) y el segundo como punto de producción agrícola-ganadero (DI GRESIA, 2014). La llegada de los capitales extranjeros y de la mano de obra inmigrante y el exponencial aumento demográfico (Figura 1), constituyeron asimismo características comunes entre ambos espacios pampeanos. Sin embargo, la proyección comercial que otorgaba a los bahienses la salida al mar contribuyó a convertir

\footnotetext{
${ }^{2} \mathrm{Al}$ respecto, pueden consultarse los trabajos de Dora Barrancos, Ma. Ángeles Sabor Riera y Nicolás Tripaldi. Véanse las referencias bibliográficas al final del presente artículo.

${ }^{3}$ El pueblo de Tres Arroyos fue instituido por decreto del gobernador de la provincia de Buenos Aires, Dardo Rocha, en 1884. Su desarrollo comenzó al año siguiente, en 1885, a partir de la inauguración del edificio municipal (DI GRESIA, 2014, p. 97).
} 
a esta localidad en una concentración urbana con pretensiones de hegemonía regional que se consolidaron durante las primeras décadas del siglo XX por efecto de la instauración de los tribunales y de la ampliación de su oferta de servicios culturales, educativos y sanitarios.

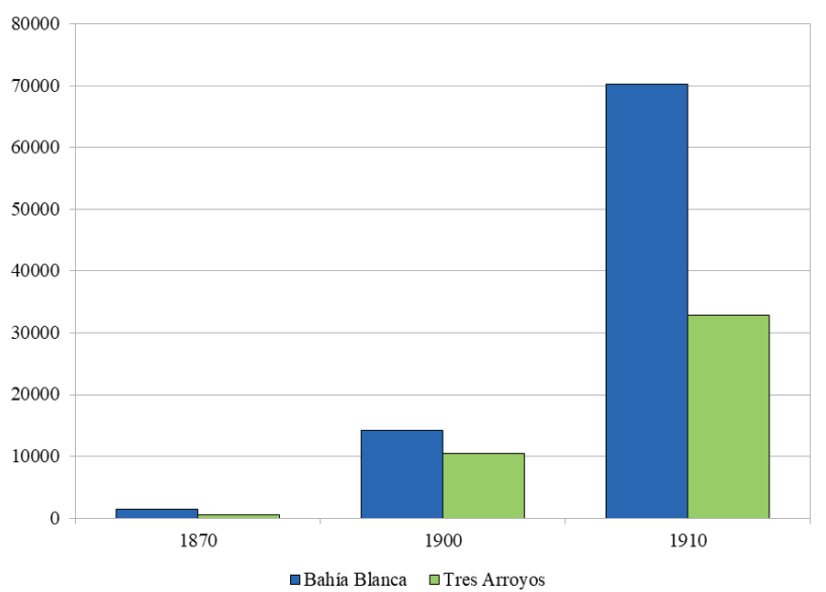

Figura 1: Población comparada de los partidos de Bahía Blanca y Tres Arroyos. [Elaboración propia en base a los censos nacionales]

Tres Arroyos, por su parte, conservó un perfil eminentemente rural (Figuras 2 y 3) ligado a las características de su economía agropecuaria, que, aunque lo mantuvo en una posición de dependencia administrativa de otros centros regionales como Tandil o Bahía Blanca, no impidió que fuera protagonista de un crecimiento también acelerado. Las condiciones de ruralidad, sin embargo, tuvieron consecuencias concretas sobre las posibilidades de incorporación al proyecto educativo y alfabetizador implementado desde el gobierno nacional, ya de por sí limitado (GANDULFO, 1991). En efecto, la campaña en su totalidad sufría los efectos educativos de la insuficiencia de escuelas y maestros, de la extensión geográfica y de la necesidad de incorporar a los niños como mano de obra familiar. De este modo, aún entrado el siglo, los índices de analfabetismo, de escolarización y de deserción continuaban siendo elevados en comparación con otros lugares de la provincia. Según el Censo Nacional de 1914, mientras en Bahía Blanca, el porcentaje de analfabetos era del 33,8\% (apenas inferior al nacional, de 35,9\%), el de Tres Arroyos alcanzaba de 49,7\%; el índice de niños que no recibían instrucción era, a su vez, del 37,6\% y del 52,2\%, respectivamente. Más allá de estas diferencias, ambos espacios constituyeron durante esta etapa "zonas grises" de la construcción estatal (PLOTKIN; ZIMMERMANN, 2012) que, por su condición periférica respecto del centro del poder, otorgaron un papel protagónico a los agentes de la sociedad civil en los procesos de modernización cultural que tornaron difusas las fronteras entre lo estatal y lo no-estatal. 


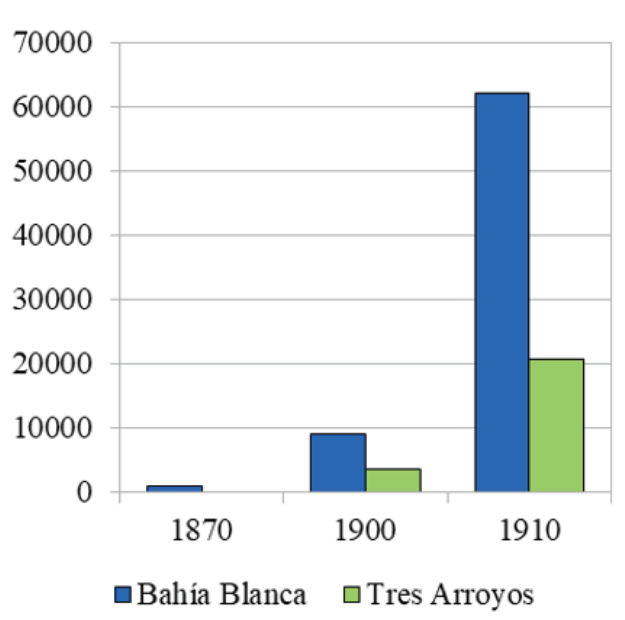

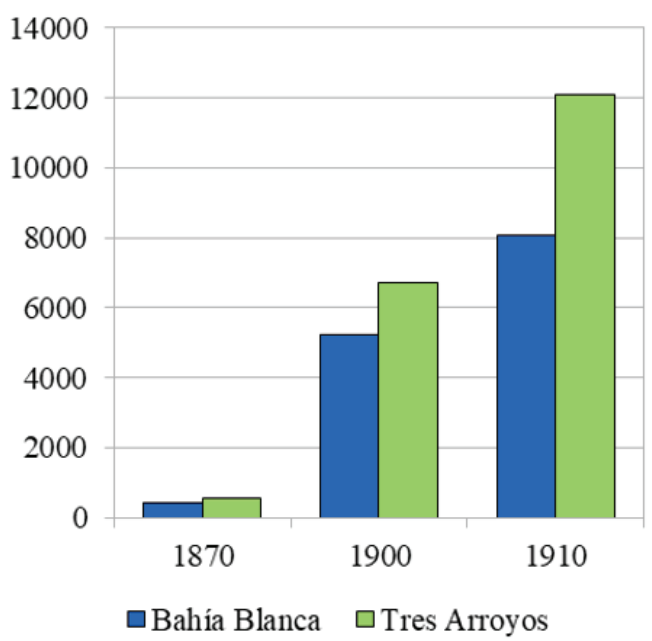

Figuras 2 y 3: Población urbana comparada de los partidos de Bahía Blanca y Tres Arroyos (izq) y Población rural comparada de los partidos de Bahía Blanca y Tres Arroyos (der). [Elaboración propia a partir de los censos nacionales]

El auge asociativo que desde fines del siglo XIX se produjo en los centros urbanos más destacados de la Argentina (DI STÉFANO, 2002), tuvo su correlato en las localidades del sudoeste bonaerense donde distintos grupos, caracterizados por la posesión de capitales diversos, se unieron en pos del ideal civilizatorio allí donde la capacidad del Estado resultaba limitada. Como uno de los pilares del mundo moderno y del progreso, la actividad asociativa era considerada un avance hacia una ciudadanía republicana articulada en torno a los valores de igualdad, libertad y fraternidad. La organización de las bibliotecas populares según el paradigma sarmientino congregaba estos significados que se veían, a su vez, potenciados por el carácter cultural de las entidades. Sus promotores, distinguidos siempre por detentar ciertos capitales educativos que confirmaban con estas intervenciones, asumían plenamente de esta manera un rol conductor en el programa de expansión lectora y cultural de las sociedades locales.

De acuerdo con ello, los años que abarcan desde la década de 1880 hasta 1910, lejos de ser un período de retracción bibliotecaria en el interior bonaerense, fueron de creación y afianzamiento de este tipo de instituciones que acompañaron y reforzaron la campaña de educación estatal en los pueblos de mayor crecimiento (Figura 4). La ausencia de bibliotecas sostenidas por cualquiera de las instancias gubernamentales permitió que estas entidades, surgidas de asociaciones civiles, fueran reconocidas hasta la actualidad por los habitantes como organismos públicos fuertemente identificados con las localidades de origen. El Estado -nacional, provincial y/o municipal - estimuló estas iniciativas a través del otorgamiento de subsidios más o menos regulares y de ayudas circunstanciales que hicieron posible, junto con el aporte de los socios, su supervivencia hasta el presente. 


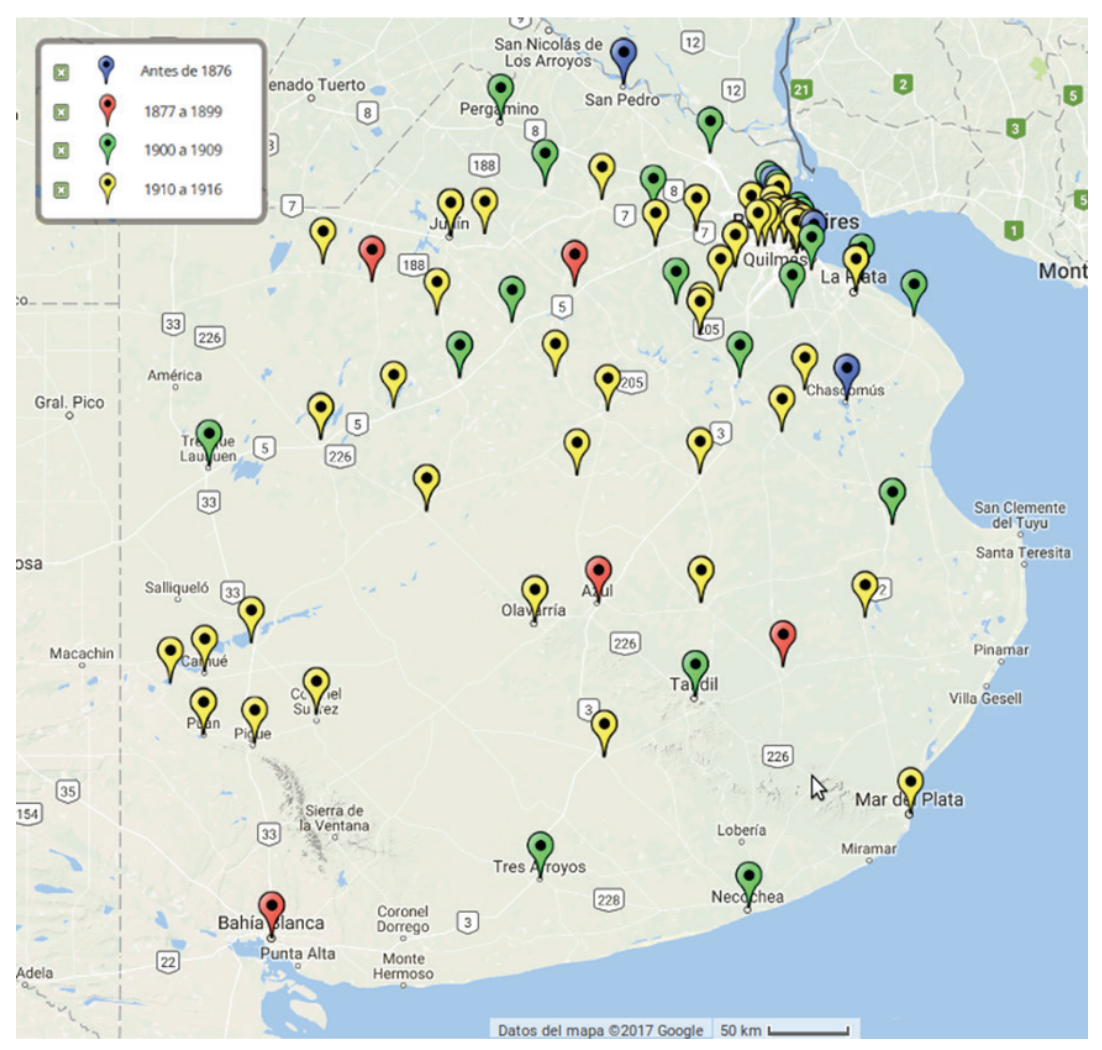

Figura 4: Bibliotecas de la provincia de Buenos Aires de acuerdo a los censos nacionales.

[Mapa de elaboración propia]

La Biblioteca Bernardino Rivadavia de Bahía Blanca fue fundada en 1882 por un grupo heterogéneo de hombres ligados a la docencia y al periodismo, profesionales algunos de ellos, militares y funcionarios de organismos oficiales como el Registro Civil o el Consejo Escolar, otros, que constituyeron la asociación homónima con el fin de crear y sostener una biblioteca popular de acceso público con una colección "lo más variada posible y para que todo el vecindario, sin exclusión de nacionalidad alguna, pueda instruirse en lo que mas le plasca” [sic]. ${ }^{4}$ Por su parte, la Biblioteca Sarmiento de Tres Arroyos abrió sus puertas en 1899 como dependencia del Centro Recreativo de Comercio (1897). A diferencia de su par bahiense, la asociación que le dio origen no tenía un carácter exclusivamente cultural, sino que su objetivo era propender "á la vinculación de sus socios, cultivando el espíritu de asociación por medio de recreos honestos, bajo la forma de bailes, veladas y las fiestas que la C.D. crea oportuno organizar y por medio de escuelas" y "defender los intereses comerciales en general, y los de los asociados en particular, cuando se trate de aquellos cuya defensa redunde en interés

\footnotetext{
${ }^{4}$ ASOCIACIÓN BERNARDINO RIVADAVIA (ABR). Libro de Actas del Consejo Directivo de la Asociación Bernardino Rivadavia 1882-1884. Bahía Blanca, 4 abr. 1882. f. 1.
} 
común". 5 En este marco, se proyectaba tanto la creación del club como de la biblioteca que, sin embargo, se halló desde sus comienzos abierta y disponible para el público en general. Este perfil corporativo, que fue abandonado en 1910 cuando se disolvió el Centro en favor de la biblioteca, marcó la extracción social y ocupacional de sus fundadores y principales impulsores que, durante los primeros diez años de su funcionamiento, fueron mayormente comerciantes.

A pesar de sus diferencias de origen y dimensiones, estas instituciones compartieron derroteros, problemas y proyectos comunes en su etapa inicial de existencia. Las vicisitudes económicas provenientes de los escuetos aportes societarios y de la inestabilidad de los asignaciones oficiales, la escasez de suscriptores y de asociados y la dificultades causadas por la ausencia de una sede social propia, fueron constantes, al menos hasta fines de la década de 1920, cuando ambas construyeron los edificios que las albergan hasta hoy como resultado de la conjunción de la donación de sendos benefactores (Luis Caronti y Juan B. Istilart, respectivamente) y de la asignación de partidas presupuestarias extraordinarias por parte del Estado.

Cabe señalar también que si bien el préstamo bibliotecario fue la actividad principal en torno a la cual se organizaron las dos entidades, esta fue complementada con otras de carácter cultural y educativo más general que denotaban la voluntad de convertir a las bibliotecas en sedes de un proyecto educativo mayor. La confianza común en el valor del libro y de la lectura como factores civilizatorios era lo que hacía posible esta integración de escuelas y bibliotecas en el programa que había recibido sanción legal a partir de promulgación de la Ley 1420 de Educación Común, gratuita y obligatoria (1884). Mientras en las aulas se enseñaba "el arte de leer, el arte de escribir y el arte de contar", en las salas de las bibliotecas debía transmitirse el gusto por la "buena lectura", facilitando el acercamiento de los sectores populares a la cultura letrada y haciéndola accesible y placentera.

\section{Hacia la configuración de un público infantil}

Esta comunidad de propósitos y fundamentos que unía a las bibliotecas populares con el sistema educativo desde sus orígenes, no se manifestó, sin embargo, en un programa de tareas orientado exclusivamente a los niños. Por el contrario, en los dos casos que nos ocupan, estos solo aparecieron reconocidos como un sector específico del público al promediar los ańos 1920. Sí el carácter corporativo inicial de la Biblioteca Sarmiento puede explicar la inexistencia de la figura del lector infantil en sus estatutos, este argumento no

\footnotetext{
${ }_{5}^{5}$ BIBLIOTECA PÚBLICA SARMIENTO (BPS). Libro de Actas del Consejo Directivo del Centro Recreativo de Comercio 1900-1933. Tres Arroyos, 15 mar. 1900. f. 5. Este artículo del reglamento fue remplazado por otro en 1908 que enunciaba como único propósito de la Asociación "fundar y sostener una Biblioteca Pública".
} 
resulta aplicable a la institución bahiense que recién la incorporó en su modificación de $1920 .{ }^{6}$ Un año más tarde, al crearse la sección circulante, los nińos pudieron incorporarse también a la categoría de "abonado" que les permitía, por un costo de $\$ 0,5$ a $\$ 1$, llevar el material a su domicilio. Hasta entonces, la lectura se realizaba con exclusividad en las salas que la biblioteca destinaba a la consulta.

A pesar de que se reconocía la importancia de facilitar el acceso bibliográfico como parte del plan de educación general y de la lucha contra el analfabetismo, la sacralidad del libro y la preocupación por la preservación de los acervos bibliotecarios reunidos con dificultad limitaba considerablemente las posibilidades reales de uso. La biblioteca, lejos de constituir un ámbito familiar y asequible para los niños, funcionaba como una heterotopía cuyas reglas era necesario internalizar (FOUCAULT, 2010, p. 26). Ingresar a sus recintos suponía entrar a un lugar-otro regulado por estrictas normas de comportamiento ajenas a lo cotidiano que implicaban una adecuación de los hábitos, los cuerpos y de los movimientos a las pautas de civilidad requeridas por el aura libresca. ${ }^{7}$ De acuerdo con las disposiciones reglamentarias de ambas instituciones, la utilización de los servicios suponía la asimilación de una serie de procedimientos que involucraban desde el cumplimiento de los plazos fijados para la devolución del material y el pago de las cuotas al reconocimiento de un sistema de organización de la información para efectuar los pedidos, el cuidado de la integridad de los textos y el sostenimiento de una conducta decorosa en las salas.

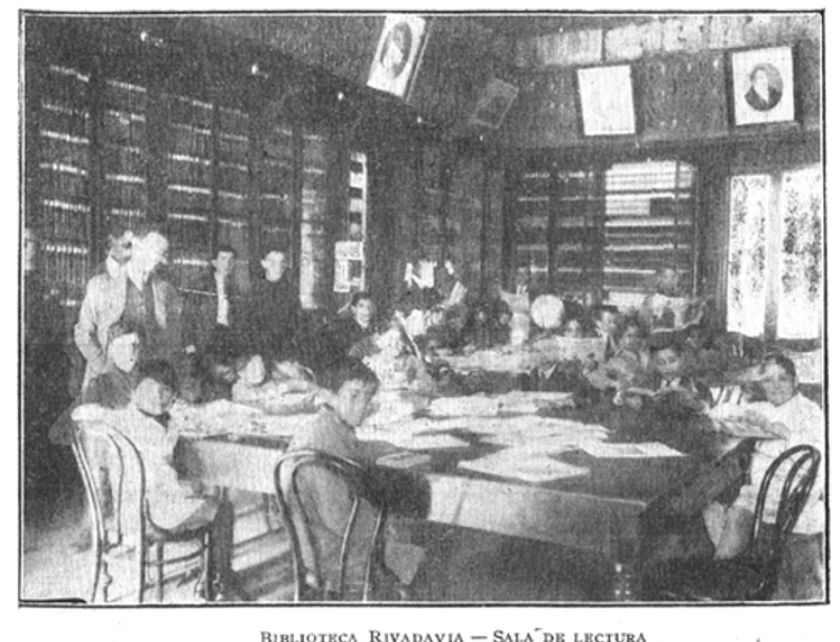

Figura 5: Sala de lectura de la Biblioteca Bernardino Rivadavia de Bahía Blanca en horario infantil. CENTENARIO de Bahía Blanca: Homenaje de La Nueva Provincia en el primer centenario de la fundación de la ciudad de Bahía Blanca, 1828-11 abril-1928. Bahía Blanca: La Nueva Provincia, 1928.

\footnotetext{
${ }^{6}$ ABR. Estatutos, de 1920. Estatutos aprobados en la Asamblea General Extraordinaria efectuada los días 25 y 27 de febrero de 1920. Bahía Blanca: Palumbo y Rojlin, 1921. p. 13.

${ }^{7}$ Al respecto véase AGESTA, 2018.
} 
La omisión de los niños en los reglamentos no implicaba que éstos no acudieran en mayor o menor medida a las bibliotecas. Los avances de los índices de alfabetización y escolaridad a los que nos hemos referido más arriba y, en el caso de Bahía Blanca, la aperturade los colegios secundarios estatales, ${ }^{8}$ incrementó notablemente la asistencia infanto-juvenil hasta el punto de generar una auténtica demanda que se canalizó mediante la creación de las secciones específicas. El proyecto de apertura de una sección infantil presentado en 1925 por un miembro del Consejo Directivo, Francisco Loge (hijo), fue implementado por la Biblioteca Rivadavia ese mismo año. Según la circular emitida por las autoridades, la biblioteca infantil estaría "convenientemente dotada de obras seleccionadas para niños" que podrían ser consultadas gratuitamente todos los días hábiles de 9 a 11 h. A manera de fundamento, se citaba un texto publicado por el diario porteńo La Prensa donde se afirmaba la necesidad de proponer la difusión de este tipo de establecimientos ${ }^{9}$ (Figura 5).

La articulación con el sistema educativo y sus fines - ligados a la construcción de una ciudadanía moderna y de una moral civilizada - se vieron reforzados en 1929 con la puesta en marcha de una biblioteca infantil ambulante destinada a funcionar en las escuelas primarias dependientes del Consejo Escolar. De acuerdo con él, se remitirían a cada escuela dos colecciones de libros para niños que permanecerían allí hasta cumplirse el plazo de un mes, luego del cual se enviarían a otro establecimiento. Los interesados podrían llevar el material a su domicilio por cinco días y sin costo. De esta manera, se pretendía orientar decididamente la acción bibliotecaria a la propagación del libro entre el alumnado, estimulando la formación de un público lector "asiduo, vasto y selecto". ${ }^{10}$

La Biblioteca Sarmiento, por su parte, inauguró su sección infantil en 1927 por iniciativa de su secretario Ramón Gorraiz Beloqui. El propósito era "familiarizar á los niños [menores de 14 años] con la Biblioteca, de modo que concurran con toda libertad y puedan leer los libros que deseen". Se trataba de un "ensayo de nueva propaganda de la Biblioteca, con vistas á la atracción y educación infantil”"11 que tuvo, de hecho, una amplia repercusión: tan solo entre mayo y diciembre de ese año fueron 380 los niños inscriptos, superando las capacidades de presupuesto, atención y espacio de la institución. ${ }^{12}$ En efecto, la imposibilidad financiera de adquirir más material de lectura para satisfacer esta demanda, provocó que en octubre de 1929 las nuevas suscripciones infantiles fuera suspendidas temporalmente hasta tanto

\footnotetext{
${ }^{8}$ Sobre la articulación de los colegios secundarios y las bibliotecas populares, véanse TASSO, 2013/2014, p. 105-109 y VIGNOLI, 2015.

${ }^{9}$ ABR. [Circular] 31 oct. 1925, Bahía Blanca. Propaganda de la creación de la Biblioteca Infantil.

${ }^{10}$ ABR. Libro de Actas del Consejo Directivo de la ABR 1922-1931. Bahía Blanca, 3 fev. 1930. p. 110.

${ }^{11}$ BPS. Libro de Actas del Consejo Directivo, 1900-1933. Tres Arroyos, 17 maio 1927. p. 365.

12 En la asamblea anual de 1927 se señaló que "la atención de tanto niño y su servicio bibliográfico lleva bastante tiempo y dinero. Se han comprado ya muchos libros exclusivamente para ellos y habrá que comprar muchos más. Por la tarde casi falta tiempo para atenderlos, pues es cuando más concurren, debido á que por la mañana está cerrada la biblioteca, y por la noche son pocos los que tienen autorización para venir". BPS. Libro de Actas del Consejo Directivo, 1900-1933. Tres Arroyos, 1927. p. 376.
} 
se cobraran los subsidios adeudados por el Estado. Para entonces se contaba ya con 400 socios de menos de 14 ańos y con un reglamento redactado en 1928 que regulaba el uso de las instalaciones ${ }^{13}$ (Figura 6). En ambos casos, fue la existencia efectiva de los pequeños lectores recién escolarizados lo que impulsó la creación de la nueva sección, contribuyendo, así, a conformar un público definido con necesidades específicas y a reforzar el proceso de expansión lectora que se impulsaba desde el Estado.

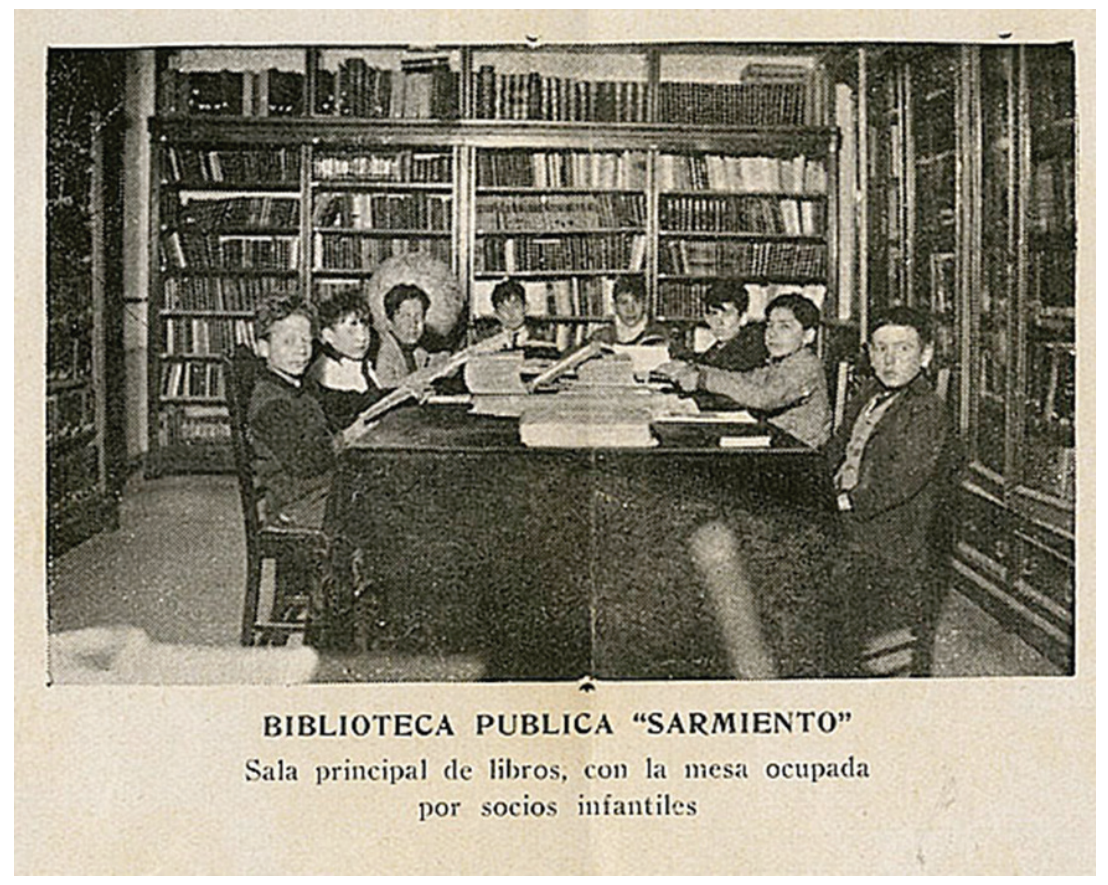

Figura 6: Niños en la Biblioteca Pública Sarmiento. Tres Arroyos, 1927. Archivo Digital de la CONABIP.

Disponible en: http://www.conabip.gob.ar/archivo_historico Acceso: 27 nov. 2018.

Para las instituciones en cuestión, la apertura de estas dependencias supuso una significativa erogación de recursos que afrontaron mediante donaciones, subvenciones, eventos benéficos y reasignaciones presupuestarias. Las necesidades que debieron cubrir para atender de forma satisfactoria a los nuevos usuarios fueron, principalmente, de dos órdenes: bibliográfico y de infraestructura. De este modo, la disponibilidad de personal y el acondicionamiento de las salas y la confección de un catálogo apropiado y variado, fueron los rubros que requirieron mayores y continuas inversiones en tanto se concebían como herramientas indispensables en la tarea de pedagogía social que asumían las bibliotecas para sí.

${ }^{13}$ BPS. Libro de Actas del Consejo Directivo, 1900-1933. Tres Arroyos, 13 mar. 1928. p. 368. 


\section{La construcción del catálogo}

En los casos que nos ocupan, por hallarse vinculadas y precedidas por instituciones para adultos, las secciones infantiles fueron adquiriendo forma tanto a partir del material ya atesorado como de la incorporación de otro de carácter específico. De este modo, se integraron al problema más amplio de la composición, organización y clasificación de los catálogos, los cuales, a su vez, fueron variando a medida que crecían los acervos institucionales.

Estos últimos se fueron configurando paulatinamente mediante tres mecanismos: canje, adquisición y donación. En el primero de ellos, fueron otras bibliotecas las principales interlocutoras. Tal como consta en la correspondencia, el pedido de intercambio de ejemplares repetidos o sobrantes era un recurso frecuente de la Comisiones Directivas para acrecentar sus fondos. En el segundo, era la dirección misma la que se ocupaba de efectuar un pedido a quien correspondiera - casa editora, librería, autores o instituciones - para obtener el material de su interés a cambio de un monto acordado con anterioridad y emanado de lo recaudado por distintas vías. Por último, se hallaban las donaciones, que provenían tanto de individuos y asociaciones particulares como de organismos y dependencias burocráticas oficiales. Sí los primeros estaban guiados por aspiraciones filantrópicas o propagandistas - muchas veces eran los mismos escritores quienes aportaban sus obras -, los segundos tenían como principales funciones la difusión de las normativas y documentos estatales, por un lado, y el sostenimiento de las bibliotecas, por el otro. Este último objetivo era el que orientaba, en particular, la acción de las comisiones de protección y fomento de bibliotecas populares de la Nación y de la provincia de Buenos Aires, cuya contribución resultó esencial para la manutención y el crecimiento de las entidades en cuestión.

Estos organismos pretendían desde sus orígenes estimular los servicios bibliotecarios mediante la asignación de recursos económicos para la compra de libros. Reactivada luego de más de treinta años, la Comisión Protectora nacional fue dotada a partir de 1911 de los fondos necesarios para desarrollar su acción; a pesar de que recién ocho años más tarde fuese aprobada por el Poder Ejecutivo la reglamentación de sus atribuciones y facultades, la comisión comenzó a operar de manera inmediata y continuó haciéndolo de forma ininterrumpida hasta 1930. De acuerdo con la documentación disponible, ésta retenía el $50 \%$ del dinero adjudicado para adquirir las obras que la biblioteca requería y entregaba trimestralmente el resto para que ellas mismas invirtieran en bibliografía que luego debían rendir ante las autoridades competentes.

El gobierno bonaerense, por su parte, emitió ya en el último cuarto del siglo XIX un decreto de fomento de las bibliotecas según el cual se creaba también una comisión ad hoc que, entre otras cosas, dispondría de la suma mensual de mil pesos $\mathrm{m} / \mathrm{n}$ para "comprar y distribuir entre las Bibliotecas Populares que funcionen, aquellas obras que más llamen la atención del mundo y para los gastos indispensables de propaganda, cuya suma se imputará á eventuales 
del Gobierno". Luego de un período de inactividad y a solicitud de la Asociación Nacional de Bibliotecas recientemente fundada, el 28 de enero de 1910 el Ejecutivo provincial creo un nuevo organismo bajo la presidencia de Jacobo Larrain que, no obstante, quedó disuelto tres años después por decreto gubernativo. De este modo, el apoyo a las bibliotecas del territorio no contó ya con una agencia específica, sino que quedó a cargo del ministerio de gobierno (SARMIENTO, 1930). Lo mismo sucedía a nivel municipal, donde las subvenciones eran discrecionales y dependían de la capacidad de gestión y de activación de vínculos personales de los equipos directivos de las bibliotecas en los gobiernos comunales.

La importancia de estos subsidios oficiales para la ampliación de los acervos queda de manifiesto en el examen numérico de su evolución. Aunque contamos con datos parciales y desiguales entre ambas bibliotecas - dado que solo se han preservado los catálogos bahienses - es posible observar ciertos saltos cuantitativos en el total de volúmenes disponibles que coinciden, en gran medida, con las etapas de favor gubernamental (Figura 7). Así, mientras en la Biblioteca Rivadavia los períodos 1905-1906 y 1909-1910 fueron de gran crecimiento en coincidencia con el otorgamiento de un subsidio provincial por $\$ 4000$, primero, y los aportes conjuntos de las Comisiones antes mencionadas, en la Biblioteca Sarmiento el aumento más significativo se produjo en la etapa 1926-1927 cuando comenzó a recibir el apoyo de la agencia nacional.

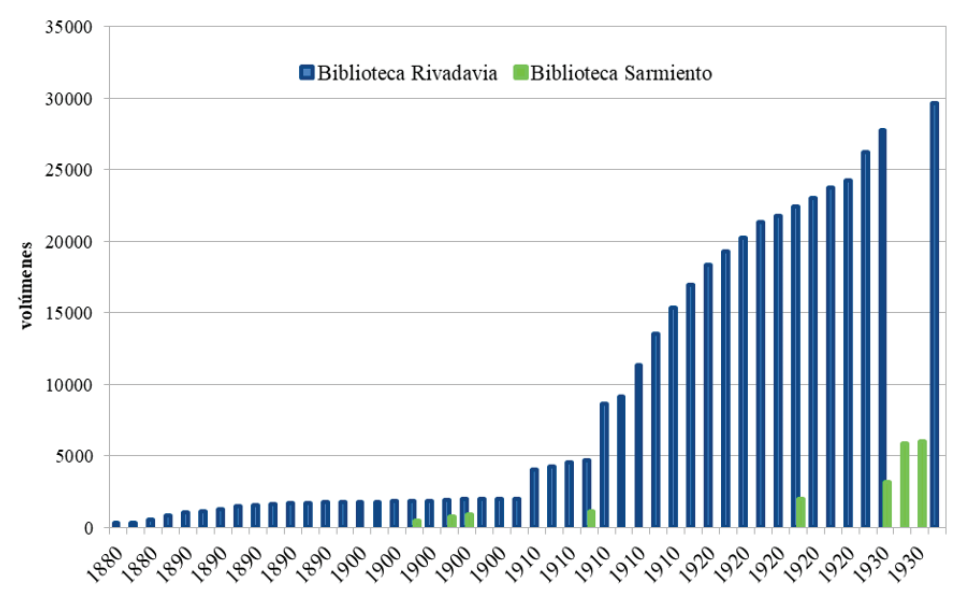

Figura 7: Número de volúmenes que integraban los acervos de la ABR y de la Biblioteca Pública Sarmiento desde sus fundaciones hasta 1929, por año. Elaboración propia a partir de fuentes varias.

Hasta la creación de estas áreas específicas, las lecturas infantiles aparecían en ambas instituciones integradas con las de adultos y separadas en función de las distintas categorías temáticas; así, para los usuarios, más allá de las recomendaciones del bibliotecario, no existían precisiones respecto de la audiencia a la que estaban destinadas las publicaciones. Los catálogos de Bahía Blanca muestran que fue recién en la edición de 1925, cuando 
se habilitó la sección correspondiente, que se introdujo una indicación referida a los lectores ideales. Bajo el título "Lectura para familias" se agruparon, de hecho, los libros considerados aptos para los nińos que se ofrecían como parte de la colección circulante. En el suplemento de 1928 se distinguieron las incorporaciones de la Biblioteca Infantil del resto, con la intención de demostrar el desarrollo del apartado y darle visibilidad entre los asociados. Sin embargo, en la edición de 1932 los libros para nińos volvieron a formar parte de las secciones generales.

Aunque gran parte del proceso bibliotecario permanece en las sombras, sabemos que la inauguración de las áreas infantiles en ambas localidades supuso dos movimientos: uno de incorporación de nuevas obras adecuadas al público menudo y otra de reestructuración del patrimonio existente. En los dos casos, el rol del bibliotecario fue fundamental, dado que su persona reunía las condiciones de conocedor del material disponible en el mercado y de mediador con los nińos lectores y sus preferencias. En la Rivadavia, se solicitó a Francisco Loge (h), quien ese momento cumplía ese rol, que hiciera un listado de los libros (108 títulos) que podrían reasignarse al uso infantil y se destinaron, además, $\$ 4000 \mathrm{~m} / \mathrm{n}$ para la adquisición de más volúmenes. En este proceso, también se solicitó la opinión vinculante de Loge que elevó una nómina de colecciones que convenía poner a disposición de los usuarios. En Tres Arroyos se solicitó a los socios en 1928 la formación de una subcomisión encargada de atender ese departamento y de perfeccionar sus catálogos, actividad que, sin embargo, continuó cumpliendo José S. Mulazzi, el bibliotecario. Desde su constitución y hasta 1930, al menos, la actualización de la biblioteca infantil fue una de las principales inversiones de la Sarmiento. Las subvenciones - nacional, provincial y municipal - se usaban allí en gran medida para satisfacer esa demanda creciente, tal como lo atestiguan los pedidos efectuados a los agentes, a las librerías y a la Comisión de fomento. La búsqueda de fondos llevó incluso a ensayar otros medios como la organización de veladas benéficas con la finalidad de recaudar dinero para la compra.

\section{Los buenos libros y los buenos niños}

Aunque no poseemos inventarios completos, los documentos internos permiten vislumbrar las preferencias de los bibliotecarios y directivos al momento de adquirir los libros y, por ende, sus representaciones sobre los propósitos que debía perseguir la lectura infantil. Como sostiene Valeria Sardi, a principios del siglo XX coexistían en los discursos pedagógicos tres concepciones distintas y complementarias sobre ella: la lectura como hábito, la lectura como formación moral y puerta al conocimiento y la lectura como cultivo de la imaginación (SARDI, 2010). Sí la primera se encontraba entre los principales fines de la biblioteca y requería de una intervención disciplinadora de parte de la institución para 
su correcto desarrollo, la segunda y la tercera suponían también una acción cuidadosa en el proceso de selección del material que se ponía a disposición de los usuarios.

La cuestión de qué leer no era menor sí se consideraba este poder modelador atribuido a la cultura escrita. Sin embargo, la necesidad de volver atractiva la oferta y contribuir al crecimiento del público, reclamó constantes negociaciones entre los lectores y las autoridades bibliotecarias. En sus elecciones de compra incidían, entonces, tanto los criterios moralizadores, las exigencias de calidad y los objetivos instructivos como los gustos infantiles canalizados mediante los pedidos bibliográficos. Por supuesto, no puede desconocerse la importancia que tuvieron en la conformación de estos catálogos las condiciones del mercado editorial y librero del momento, sobre todo en localidades alejadas de los grandes centros urbanos, y las transformaciones que estaban sufriendo estos circuitos durante la segunda mitad de la década de 1920 .

Las adquisiciones se efectuaban por intermedio de las Comisiones de fomento o bien directamente a los proveedores locales o nacionales. En todos los casos, las empresas enviaban sus listados de novedades y, una vez escogidos los títulos de acuerdo al presupuesto disponible y a los intereses de las bibliotecas, se remitían los ejemplares solicitados. Dado que se trataba de compradores frecuentes y con fines benéficos, las firmas solían otorgarles facilidades de pago y descuentos que alcanzaban hasta el 50\% del monto total. Ante la decisión de crear las secciones infantiles, los encargos de libros para ellas y de catálogos actualizados de esa oferta editorial pasaron a un primer lugar entre las preocupaciones de las respectivas comisiones directivas. Las propuestas de adquisición de los bibliotecarios se hallaron, por lo tanto, mediadas por su conocimiento y por la disponibilidad del material. De allí, que en las nóminas presentadas se indicara el nombre de las colecciones completas antes que de los autores o de las obras. En la entidad bahiense, por ejemplo, Loge elevó una nota a la C.D. sugiriendo la incorporación de las Bibliotecas Perla, Enciclopédica, Ilustrada para niños y Escolar Recreativa de Editorial Calleja; la Biblioteca para niños de Sopena y la Colección Araluce, entre otras. ${ }^{14}$ Luego, a este listado inicial se añadió la compra 67 volúmenes de la francesa Récréation que, junto con parte de los anteriores, sumaron un valor total de $\$ 150 \mathrm{~m} / \mathrm{n}$. Como podemos ver, la enumeración incluía dos colecciones de las casas barcelonesas Araluce y Sopena y al menos cuatro de la madrileńa Calleja, cuyas producciones habían tenido desde los primeros años del siglo XX una gran difusión entre los lectores de habla hispana. ${ }^{15}$ La descripción somera con que Loge acompañó su misiva

\footnotetext{
${ }^{14}$ ABR. Correspondencia recibida. De 1921 en adelante. Bahía Blanca, 24 jun. 1925.

${ }^{15}$ Como indica Jaime García Padrino, esto se debió debido al hecho de que Calleja contó desde finales del siglo XIX con una importante base en México para su difusión en el continente americano como parte de la implementación una política editorial moderna de la literatura infantil que la transformó en precursora de otros planteamientos actuales. La distribución de las ediciones de Calleja tuvo un carácter multinacional, ya que hacia 1914 poseía 18 delegaciones en países americanos hispanoparlantes y en Filipinas. Véase GARCÍA PADRINO, 2015 y GARCÍA PADRINO, 1996, p. 299-343.
} 
daba cuenta de los parámetros que operaban en la selección: precios accesibles, materialidad atractiva y manejable, profusión ilustrativa y calidad de contenidos que hicieran posible "instruir deleitando" así como "formar el buen gusto" de los pequeños mediante la lectura de adaptaciones de textos consagrados. ${ }^{16}$

Similares, aunque más variados, fueron los pedidos de la entidad tresarroyense que incluyeron colecciones como Biblioteca Oro y Colección Papa Moscas de Hijos de Santiago Rodríguez de Burgos; Publicaciones Mundial de Barcelona; Biblioteca Espasa Calpe; Biblioteca Selecta y Biblioteca para niños de Sopena; y Cuentos nuevos en colores, Biblioteca Enciclopédica para niños y Biblioteca Tinstrala para niños de Calleja. La edición española era, sin dudas, la dominante y la literatura edificante, los "clásicos" y las novelas de aventuras, los géneros favoritos. Hacia fines de la década del veinte, en ambas instituciones comenzaron a solicitarse también, cada vez con mayor frecuencia, publicaciones nacionales, en especial de la Editorial Atlántida. Esto se correspondía con la expansión y la modernización del mercado que se estaba produciendo en el país luego de la coyuntura favorable que había supuesto para la industria local la retirada transitoria de las casas editoras europeas durante la Primera Guerra Mundial (DELGADO; ESPÓSITO, 2006). La literatura infantil, estimulada por el avance de la escolarización, de la alfabetización y de la vida urbana, no fue ajena a estos cambios. En este contexto, la figura de Constancio C. Vigil - escritor y director de Atlántida - se volvió emblemática del desarrollo del sector, a la vez que se convirtió uno de sus referentes indiscutidos, ${ }^{17}$ demostrando que el tono fuertemente moralista y de filiación cristiana de Vigil no se hallaba reñido con los gustos del público menudo.

Esto, sin embargo, no siempre era así. A pesar de las prevenciones contra los "malos libros (MESTRE, 1920), ${ }^{18}$ las preferencias por las "novelitas" folletinescas y de aventuras se volvían manifiestos en los autores y títulos solicitados por los usuarios. La necesidad de conciliar estos intereses con el amor por "los libros útiles y selectos", fue asumida por los organismos oficiales y por las bibliotecas populares mediante diversos mecanismos. La Comisión Protectora de la provincia de Buenos Aires, dirigida por Augusto Belín Sarmiento informó en 1888 que dicha entidad suministraría a la Biblioteca Rivadavia "obras adecuadas al género de lectura que resulta de mayor demanda según las estadísticas comunicadas", para lo cual aconsejó a las autoridades llevar un registro diario de las obras más pedidas por los lectores. ${ }^{19}$

Asimismo, la Biblioteca Sarmiento, en su asamblea de diciembre de 1927, resolvió la formación de una subcomisión encargada de elaborar la nómina de los libros deseados por los lectores. De los nuevos pedidos confeccionados en base a estos listados se evidencia

\footnotetext{
${ }^{16}$ Estos eran los criterios que orientaban también a los editores para la infancia antes mencionados.

${ }^{17}$ Sobre la Constancio C. Vigil y la Editorial Atlántida, véase BONTEMPO, 2012.

${ }^{18}$ Sobre los peligros de la lectura pueden consultarse AGESTA, 2013, p. 35-60 y AGESTA, 2016.

${ }^{19}$ BELÍN SARMIENTO, Augusto (La Plata, ARG). Carta para: Comisión Directiva de la Biblioteca Popular Bernardino Rivadavia (Bahía Blanca, ARG) 20 fev. 1888. f. 197.
} 
la predilección - muchas veces compartida por los adultos ${ }^{20}$ - por autores como Jules Verne, Emilio Salgari y Alexandre Dumas. Sus novelas, donde se daban citan la aventura, la divulgación científica e histórica y lirismo propios de la literatura decimonónica (CARRILLO, 2016, p.74), representaban los intereses de la pequeña burguesía y de las clases medias, favoreciendo la identificación y la imaginación y convirtiéndolos en auténticos clásicos infantiles más allá de los recelos letrados.

\section{Conclusiones}

La conformación del sistema bibliotecario adquirió en Argentina rasgos particulares que, a diferencia de lo sucedido en otros países latinoamericanos, asignaron a la iniciativa privada un papel fundamental en la gestión y el sostenimiento de dichas instituciones culturales. Retomando el modelo estadounidense de las sociedades de lectores promovido por Sarmiento, los gobiernos nacional y provincial arbitraron medios legislativos y presupuestarios para apoyar el desarrollo, la multiplicación y la supervivencia de las bibliotecas sin la necesidad de afrontar la estructuración de una organización de carácter público y centralizado. En efecto, durante el último cuarto del siglo XIX, el Estado en proceso de consolidación delegó parte de las responsabilidades del programa educativo a la sociedad civil que asumió así un rol activo en el proyecto civilizatorio moderno. De esta manera, las bibliotecas estuvieron atravesadas permanentemente por las tensiones entre sus voluntades autonómicas y la dependencia de los recursos oficiales y se vieron sometidas a los vaivenes de los organismos burocráticos y de la disponibilidad de fondos.

En el sudoeste de la provincia de Buenos Aires - "zona gris" de la presencia estatal a fines del 900 que, sin embargo, estaba siendo protagonista de un crecimiento inusitado la creación de bibliotecas populares como la Bernardino Rivadavia en Bahía Blanca y la Sarmiento en Tres Arroyos fue un signo y, a la vez, un agente del "progreso" deseado. Aun cuando las condiciones estructurales no les fueran favorables, los grupos letrados se hicieron cargo de la tarea de difusión de lectura y de reforzamiento de la legitimidad de la cultura escrita, afianzando en el proceso su propia posición social en las nuevas localidades. El alcance limitado del sistema educativo en las regiones alejadas de los centros - sobre todo, en las áreas rurales -, confirió a estas instituciones un lugar preponderante en ambas ciudades, para cuyas poblaciones pasaron a ser concebidas como entidades de carácter público. En este sentido, fueron tanto el resultado como las productoras de un lectorado en aumento y con facciones específicas, diferenciadas por edad, género y clase.

\footnotetext{
${ }^{20}$ Sobre los consumos lectores en otras localidades de la provincia, pueden consultarse PASOLINI, $1997 \mathrm{y}$ QUIROGA, 2003.
} 
La apertura de las secciones infantiles en la segunda mitad de los años veinte formó parte, de hecho, de este fenómeno. Los niños, franja imprecisa del público bibliotecario hasta entonces, fueron definidos como un sector particular con necesidades de infraestructura, atención y lectura distintas a las de los adultos. En concordancia con los objetivos escolares y apoyadas por las comisiones oficiales, la Rivadavia y la Sarmiento encararon un plan de transformación interna que pretendía tanto dar respuesta a las demandas de un número creciente de usuarios recientemente escolarizados como ir moldeando sus hábitos, gustos y comportamientos de acuerdo con los parámetros de la cultura moderna occidental. El equipamiento de salas especiales, la delimitación de horarios diferenciados, la redacción de reglamentos fijando reglas de conducta y procedimientos acompañaron, así, la definición de un catálogo actualizado y adecuado para los niños.

La incorporación de material bibliográfico implicó un problema desde el punto de vista económico que las bibliotecas afrontaron con la ayuda de los organismos estatales, así como también un desafío institucional para los equipos directivos que no contaban con personal formado en el área y profesionalizado. En este marco, los modelos de otros establecimientos análogos o afines con los que se sostenía una red de intercambios fueron tan centrales como la oferta editorial y librera del momento y los contactos del personal con los socios. De esta manera, los discursos oficiales sobre la lectura infantil según los cuales entretenimiento, estudio y moral debían ir de la mano, tenían que conciliarse con los intereses de una industria en expansión y con las preferencias de los lectores. Frente a las obras didácticas e instructivas promovidas por los pedagogos, los niños eran seducidos por las novelas de intrigas y aventuras cuyo despliegue imaginativo habilitaba una experiencia intensa y total (PATTE, 2008. p. 68-69). Escindidas entre sus fines educativos y el requerimiento de sus lectores, las bibliotecas fueron conformando, así, sus acervos en una negociación permanente entre el ideal prescriptivo, las posibilidades de acceso y las expectativas individuales en juego.

\section{Fuentes primarias}

ASOCIACIÓN BERNARDINO RIVADAVIA (ABR). Libro de Actas del Consejo Directivo de la Asociación Bernardino Rivadavia 1882-1884. Bahía Blanca, 4 abr. 1882. f. 1.

ASOCIACIÓN BERNARDINO RIVADAVIA (ABR). Estatutos, de 1920. Estatutos aprobados en la Asamblea General Extraordinaria efectuada los días 25 y 27 de febrero de 1920. Bahía Blanca: Palumbo y Rojlin, 1921. p. 13.

ASOCIACIÓN BERNARDINO RIVADAVIA (ABR). Correspondencia recibida. De 1921 en adelante. Bahía Blanca, 24 jun. 1925.

ASOCIACIÓN BERNARDINO RIVADAVIA (ABR). [Circular] 31 oct. 1925, Bahía Blanca. Propaganda de la creación de la Biblioteca Infantil. 
ASOCIACIÓN BERNARDINO RIVADAVIA (ABR). Libro de Actas del Consejo Directivo de la ABR 1922-1931. Bahía Blanca, 3 fev. 1930. p. 110.

BELÍN SARMIENTO, Augusto (La Plata, ARG). Carta para: Comisión Directiva de la Biblioteca Popular Bernardino Rivadavia (Bahía Blanca, ARG), 20 fev. 1888. f. 197.

BIBLIOTECA PÚBLICA SARMIENTO (BPS). Libro de Actas del Consejo Directivo del Centro Recreativo de Comercio 1900-1933. Tres Arroyos, 15 mar. 1900. f. 5.

BIBLIOTECA PÚBLICA SARMIENTO (BPS). Libro de Actas del Consejo Directivo, 19001933. Tres Arroyos, 17 maio 1927. p. 365.

BIBLIOTECA PÚBLICA SARMIENTO (BPS). Libro de Actas del Consejo Directivo, 19001933. Tres Arroyos, 1927. p. 376.

BIBLIOTECA PÚBLICA SARMIENTO (BPS). Libro de Actas del Consejo Directivo, 19001933. Tres Arroyos, 13 mar. 1928. p. 368.

\section{Referencias}

AGESTA, María de Las Nieves. El ojo y el oído: Cuerpos lectores, educación infantil y bibliotecas populares en el sudoeste bonaerense durante los años 20. En las Jornadas de Historia de la Patagonia: Miradas sobre el pasado, el presente y el futuro, VIII, 2018, Viedma. Comunicación.

AGESTA, María de Las Nieves. La mirada bajo custodia. Bahía Blanca a comienzos del siglo XX. En: RIBAS, Diana I. (coord.). Los límites de las imágenes. Bahía Blanca: 17grises editora, 2013. p. 35-60.

AGESTA, María de Las Nieves. Páginas modernas. Revistas culturales, transformación social y cultura visual en Bahia Blanca entre 1902 y 1927. Bahía Blanca: Ediuns, 2016.

BARRANCOS, Dora. Educación, cultura y trabajadores (1890-1930). Buenos Aires: Centro Editor de América Latina, 1991.

BONTEMPO, María Paula. Editorial Atlántida. Un continente de publicaciones, 1918-1936.

Tesis (Doctorado en Historia) - Universidad de San Andrés, Buenos Aires, 2012.

CARRILLO, Pedro C. El lector literario. México: Fondo de Cultura Económica, 2016.

DELGADO, Verónica; ESPÓSITO, Fabio. 1920-1937. La emergencia del editor moderno. En: DE DIEGO, José Luis (ed.). Editores y politicas editoriales en Argentina, 1880-2000. Buenos Aires: Fondo de Cultura Económica, 2006. p. 59-90.

DI GRESIA, Leandro. Instituciones, prácticas y culturas judiciales. Una historia de la Justicia de Paz en la Provincia de Buenos Aires: el Juzgado de Paz de Tres Arroyos (1865-1935). Tesis (Doctorado en Historia) - FHyCE, UNLP La Plata, 2014, p. 97. Disponible en: http:// 
www.memoria.fahce.unlp.edu.ar/library?a=d\&c=tesis\&d=Jte1065. Acceso: 27 nov. 2018. DI STÉFANO, Roberto et al. De las cofradias a las organizaciones de la sociedad civil. Historia de la iniciativa asociativa en Argentina, 1776-1990. Buenos Aires: Edilab, 2002.

FOUCAULT, Michel. El cuerpo: las heterotopías. Buenos Aires: Nueva Visión, 2010.

GANDULFO, Alberto. La expansión del sistema escolar argentino. Informe estadístico. En: PUIGGRÓS, Adriana (dir.). Historia de la educación argentina III. Sociedad civil y Estado en los orígenes del sistema educativo argentino. Buenos Aires: Galerna, 1991. p. 309-338.

GARCÍA PADRINO, Jaime. El libro infantil en el siglo XX. En: ESCOBAR SOBRINO, Hipólito (coord.). Historia ilustrada del libro español. La edición moderna. Siglo XIX y XX. Madrid: Pirámide, 1996. p. 299-343.

GARCÍA PADRINO, Jaime. La literatura infantil iberoamericana, ¿esa gran desconocida? América sin nombre, Alicante, $\mathrm{n}^{\circ}$ 20, p. 11-25, 2015. Disponible en: http://rua.ua.es/dspace/ handle/10045/53484. Acceso: 28 nov. 2018.

GUTIÉRREZ, Leandro; ROMERO, Luis A. Sectores populares, cultura y política: Buenos Aires en la entreguerra. Buenos Aires: Siglo XXI Editores, 2007.

PASOLINI, Ricardo O. Entre la evasión y el humanismo. Lectura, lectores y cultura de los sectores populares: la Biblioteca Juan B. Justo de Tandil, 1928-1945. Anuario IEHS, Tandil, no 12, p. 373-401, 1997.

PATTE, Geneviève. Déjenlos leer: Los niños y las bibliotecas. México: Fondo de Cultura Económica, 2008.

PLANAS, Javier. Libros, lectores y lecturas: constitución, expansión y crisis de las bibliotecas populares en la Argentina (1870-1890). Tesis (Doctorado en Ciencias Sociales) - FHyCE, UNLP, La Plata, 2015. Disponible en: http://www.memoria.fahce.unlp.edu.ar/tesis/ te.1231/te.1231.pdf. Acceso: 25 ago. 2018.

PLOTKIN, Mariano B.; ZIMMERMANN, Eduardo (comps.). Los saberes del Estado. Buenos Aires: Edhasa, 2012.

QUINTANA PALI, Guadalupe; GIL VILLEGAS, Cristina; TOLOSA SÁNCHEZ, Guadalupe. Las bibliotecas públicas en México: 1910-1940. México: Dirección General de Bibliotecas, 1988.

QUIROGA, Nicolás. Lectura y política. Los lectores de la Biblioteca Popular Juventud Moderna de Mar del Plata (fines de los años treinta y principios de los cuarenta). Anuario IEHS, Tandil, no 18, p. 449-474, 2003.

RIBAS, Diana I. Del fuerte a la ciudad moderna: imagen y autoimagen de Bahía Blanca. Tesis (Doctorado en Historia) - Depto. de Humanidades, UNS, Bahía Blanca, 2008.

SABATO, Hilda. La politica en las calles. Entre el voto y la movilización. Buenos Aires, $1862-$ 1880. Buenos Aires: Sudamericana 1998. 
SABOR RIERA, Ma. Ángeles. Contribución al estudio histórico del desarrollo de los servicios bibliotecarios de la Argentina del siglo XIX: parte 2: 1852-1910. Resistencia: Universidad Nacional del Nordeste, 1975.

SARDI, Valeria. El desconcierto de la interpretación: historia de la lectura en la escuela primaria argentina entre 1900 y 1940. Santa Fe, Argentina: UNL, 2010.

SARMIENTO, Domingo F. Espíritu de asociación. En: SARMIENTO, Domingo F. Páginas selectas de Sarmiento sobre bibliotecas populares. Buenos Aires: Comisión Nacional de Homenaje a Sarmiento, 1939.

SARMIENTO, Nicanor. Historia del libro y de las bibliotecas argentinas. Buenos Aires: Imprenta Luis Veggia, 1930.

TASSO, Alberto. La Biblioteca Sarmiento de Santiago del Estero (1880-1915). Políticas de la memoria, Buenos Aires, CeDInCI, n. 4, p. 105-109, ver. 2013/2014.

TRIPALDI, Nicolás M. La política y los centros de lectura: los socialistas fundan sus primeras bibliotecas en la ciudad de Buenos Aires 1894-1899. Revista de Biblioteconomia de Brasilia, Brasilia, v. 20, n. 1, p. 41-51, 1996.

TRIPALDI, Nicolás M. Las mujeres de la política, los niños de la calle y las bibliotecas: apostillas bibliotecológicas sobre el tema de la asociación de bibliotecas y recreos infantiles. Información, Cultura y Sociedad, Buenos Aires, n. 7, p. 81-101, 2002.

VIGNOLI, Marcela. Sociabilidad y cultura politica. La Sociedad Sarmiento de Tucumán, 1880-1914. Rosario: Prohistoria, 2015. 